\title{
Chimeric Antigen Receptor Therapy for Cancer
}

\author{
David M. Barrett, Nathan Singh, David L. Porter, Stephan A. Grupp, and Carl H. June \\ Abramson Cancer Center and the Departments of Medicine, Pediatrics, and Pathology and \\ Laboratory Medicine, Perelman School of Medicine, University of Pennsylvania, Philadelphia, \\ Pennsylvania 19104
}

David M. Barrett: barrettd@email.chop.edu

\begin{abstract}
Improved outcomes for patients with cancer hinge on the development of new targeted therapies with acceptable short-term and long-term toxicity. Progress in basic, preclinical, and clinical arenas spanning cellular immunology, synthetic biology, and cell-processing technologies has paved the way for clinical applications of chimeric antigen receptor- based therapies. This new form of targeted immunotherapy merges the exquisite targeting specificity of monoclonal antibodies with the potent cytotoxicity and long-term persistence provided by cytotoxic $\mathrm{T}$ cells. Although this field is still in its infancy, clinical trials have already shown clinically significant antitumor activity in neuroblastoma, chronic lymphocytic leukemia, and B cell lymphoma, and trials targeting a variety of other adult and pediatric malignancies are under way. Ongoing work is focused on identifying optimal tumor targets and on elucidating and manipulating both cell- and host-associated factors to support expansion and persistence of the genetically engineered cells in vivo. The potential to target essentially any tumor-associated cell-surface antigen for which a monoclonal antibody can be made opens up an entirely new arena for targeted therapy of cancer.
\end{abstract}

\section{Keywords}

adoptive transfer; chimeric antigen receptor; gene transfer; synthetic biology; T cell receptor

\section{INTRODUCTION}

A variety of cellular therapies have been incorporated into cancer treatment. These include the infusion of polyclonal or antigen-specific T cells, lymphokine-activated killer cells, natural killer (NK) cells, dendritic cells, and macrophages. In this review, we describe the background, rationale, and current clinical use and experimental approaches for adoptive $\mathrm{T}$ cell therapies for the treatment of cancer utilizing chimeric antigen receptors (CARs).

Copyright ( 2014 by Annual Reviews. All rights reserved DISCLOSURE STATEMENT

The University of Pennsylvania has entered into a partnership with Novartis for the development of chimeric antigen receptors. This partnership is managed in accordance with the University of Pennsylvania's Conflict of Interest Policy. All authors are in compliance with this policy. 


\section{History and Rationale for Adoptive T Cell Transfer Therapy}

The concept of adoptive cellular therapy for tumor allografts was first reported for rodents more than 50 years ago by Mitchison (1). It was also shown that an allogeneic hematopoietic graft was important in eradicating leukemia cells after transplantation in mice $(2,3)$. In fact, the concept that the graft itself had antileukemia properties provided the early rationale to pursue clinical allogeneic bone marrow transplant (4). The results of early trials using autologous or allogeneic lymphocytes were not promising, perhaps not surprisingly as they were carried out before the principles of $\mathrm{T}$ cell biology and tumor antigens were well understood. The field of adoptive cellular therapy during the first 25 years has been reviewed by Rosenberg \& Terry (5).

The seminal finding by Weiden and colleagues (6) that hematopoietic stem cell transplantation (HSCT) using syngeneic donors was less effective at preventing relapse of leukemia than use of sibling donors provides a founding rationale for adoptive $\mathrm{T}$ cell therapy. Allogeneic T cells can recognize targets on leukemia cells that syngeneic $\mathrm{T}$ cells cannot; therefore, there may be ways to target cancer cells specifically with adoptively transferred autologous T cells (Figure 1).

\section{Principles of T Cell Transfer}

Successful adoptive $\mathrm{T}$ cell therapy is predicated on an understanding of the relevant principles of cellular and molecular immunology and cancer cell biology. Lessons learned from the disappointing efficacy of many previous forms of adoptive cellular therapy led to insights into basic $\mathrm{T}$ cell function, which in turn fueled more effective translational science.

Adoptively transferred $\mathrm{T}$ cells engraft and expand more efficiently in a lymphopenic host, as this environment supports homeostatic expansion. Factors supporting homeostatic expansion include the degree of host lymphodepletion and availability of T cell-supportive cytokines (7). Homeostatic expansion also results in the acquisition of enhanced effector functions of the infused cells (8).

The optimal engineered T cells will likely vary depending on the tumor and goals of the adoptive therapy. Originally, it was thought that effector T cells were superior because they secreted high levels of effector cytokines and were proficient killers of tumor targets in vitro. However, at present there is evidence that infusion of na"ive T cells (9), central memory $\mathrm{T}$ cells ( $\mathrm{T}_{\mathrm{CM}}$ cells) (10), Th17 cells (11), and $\mathrm{T}$ stem memory cells (12) may all have certain advantages related to their high replicative capacity. Choosing one of these subsets for expansion and modification is attractive but difficult, as the $\mathrm{T}$ cell pool available for collection from a patient may be limited. Although na"ive $\mathrm{T}$ cells or $\mathrm{T}_{\mathrm{CM}}$ cells would be expected to have excellent expansion, Th17 cells are versatile and can recruit the neutrophil compartment via their cytokine secretion profile to provide additional antitumor immune responses. Conversely, the interfering presence of regulatory $\mathrm{T}$ cells ( $\mathrm{T}$ regs) must be minimized both in the patient and in the transferred product, and some preclinical models predict high levels of $\mathrm{T}$ regs in the host will block an antitumor response of transferred lymphocytes (13). 
Preservation of telomere length and replicative capacity correlates with the engraftment efficiency and antitumor efficacy of adoptively transferred $\mathrm{T}$ cell lines in patients with melanoma (14). CD28 stimulation maintains telomere length in T cells (15), and cultures that optimize costimulation might also improve the replicative capacity of adoptively transferred $\mathrm{T}$ cells.

In addition, $\mathrm{T}$ cells can be engineered for resistance to cell-extrinsic forms of immunosuppression such as those mediated by TGF- $\beta$ and T regs $(16,17)$. Therefore, as with other forms of immunotherapy, it is probable that the ultimate clinical application of adoptive $\mathrm{T}$ cell transfer will employ combinatorial approaches of $\mathrm{T}$ cell subsets modified in various ways. This is especially true as one targets different tumor types, because the $\mathrm{T}$ cells collected from patients will have been exposed to different chemotherapy regimens (and thus may have different subsets available for collection), and the specific tumor microenvironments (e.g., lymph node, pancreas, brain) may require different approaches because tumors utilize distinct mechanisms of evasion from the immune system.

\section{STRATEGIES FOR T CELL CULTURE AND ENGINEERING}

Early studies of T cell immunotherapy transferred large numbers of effector T cells, although we now know that these cells were essentially nonreplicative and therefore unable to expand in the patient to achieve an effector-to-target ratio in vivo that would be sufficient to eradicate advanced cancers. Recent results from trials with engineered $\mathrm{T}$ cells $(18,19)$ have shown that the infusion of small numbers of cells may suffice as most of the $\mathrm{T}$ cell expansion can occur in the host rather than ex vivo in cell culture. One exception to this new approach may be in the setting of transiently engineered cells such as mRNA-transfected T cells that require large numbers of cells to be infused on multiple occasions $(20,21)$.

\section{Approaches for T Cell Culture}

Studies indicate that, on a per cell basis, the adoptive transfer of T cells with extensive replicative capacity has greater engraftment and antitumor effects than transfer of terminally differentiated effector cells that have a more potent cytotoxic effector function (14). This paradox is likely explained by the ability of $\mathrm{T}_{\mathrm{CM}}$ cells to self renew and differentiate into effector $\mathrm{T}$ cells in vivo, whereas terminal effector memory $\mathrm{T}$ cells have lost this plasticity (22). One approach is to isolate $\mathrm{T}_{\mathrm{CM}}$ cells with the desired specificity in vitro by sorting or other means of physical separation, engineer the desired specificity, expand and then infuse the $\mathrm{T}_{\mathrm{CM}}$ cells (10). Manipulation of bulk T cell- culture conditions may also enrich and maintain $\mathrm{T}_{\mathrm{CM}}$ cells and thereby obviate the need for cell sorting. Cell-culture conditions that augment CD28 and CD137 (4-1BB) costimulation in vitro promote the maintenance of $\mathrm{T}_{\mathrm{CM}}$ cells in vitro $(23,24)$ and in vivo $(25)$. The use of memory stem cells, those programmed for the most extensive self renewal, also has significant potential $(12,26)$.

An efficient cell-culture approach is to produce artificial antigen-presenting cells, either by coating beads with CD3-specific antibody or by transfecting cells to express CD3-engaging moieties and costimulatory molecules. 


\section{Approaches for T Cell Engineering}

Advances in basic science have presented a plethora of approaches to engineer lymphocytes at the genomic, RNA, epigenetic, and protein levels (27). For T cell-based therapies, vectors derived from gamma retroviruses or lentiviruses have been most useful for long-term gene expression because of their ability to integrate into the host genome, with potentially permanent expression of the transgene, and for their low intrinsic immunogenicity $(28,29)$.

For some applications, permanent transgene expression may not be required to achieve substantial therapeutic effects. RNA-based electroporation of lymphocytes using in vitrotranscribed mRNA mediates transient expression of proteins for approximately one week and obviates the risk of integrating viral vectors. Redirected $\mathrm{T}$ cells transduced with RNA encoding CARs have the expected gains of function (20), summarized in Figure 2. Clinical trials using mRNA-transduced dendritic cells have been safely conducted (30), and trials using mRNA-electroporated T and NK lymphocytes are ongoing at several centers.

\section{Strategies Using Synthetic Biology with Engineered T Cells}

The high level of tolerance to most tumor antigens combined with immunosuppressive tumor microenvironments makes simple transfer of native isolated antitumor T cells unlikely to be successful. Synthetic biology combines elements of engineering, chemistry, computer science, and molecular biology to assemble cellular and biological tools necessary to improve the natural function of the infused T cells (31).

In order to apply the principles of synthetic biology to tumor targeting, some modification of $\mathrm{T}$ cells (genetic or otherwise) is necessary. A potential safety concern when infusing individuals with engineered $\mathrm{T}$ cells is one that arose with genetically engineered hematopoietic stem cells (32), when viral insertional mutagenesis was shown to cause cellular transformation. However, in patients with congenital and acquired immunodeficiency, genetically modified $\mathrm{T}$ cells can persist after adoptive transfer for more than a decade without adverse effects $(33,34)$, indicating that genetically modifying mature human $\mathrm{T}$ cells is fundamentally safe.

\section{CLINICAL APPROACHES FOR ADOPTIVE CELL THERAPY}

\section{Tumor-Infiltrating Lymphocytes}

The adoptive transfer of tumor-infiltrating T lymphocytes (TILs), expanded from resected melanoma specimens and selected for reactivity with tumor-associated peptides, can mediate durable tumor regression in a subset of patients with advanced metastatic melanoma (35).

In noncontrolled sequential trials, TIL therapy in the setting of autologous HSCT with highdose chemotherapy and total body irradiation appears superior to TILs given with less intense host immunosuppression (35). Technical issues with producing tumor-specific $\mathrm{T}$ cells currently present a formidable barrier to conducting randomized clinical trials using TILs. 


\section{Cytotoxic T Lymphocyte Therapy}

Major histocompatibility complex (MHC) class I restricted tumor-specific cytotoxic T lymphocytes are difficult to generate owing to a dearth of tumor-associated antigens that are common to human tumors of a given type. The antigenic targets for $\mathrm{T}$ cell therapy can be parsed into six major categories (Table 1). All six classes of antigens have been targeted with acceptable safety with therapeutic vaccines, but it is likely that only tumor-specific targets will have an acceptable therapeutic index with adoptive cellular therapy.

\section{Combination Approaches Using Vaccines and Adoptive T Cell Transfer}

In mice, adoptive $\mathrm{T}$ cell therapy enhances the effects of therapeutic vaccines (36), and this combined approach in the setting of lymphopenia results in a further enhancement of tumor immunity $(37,38)$. In humans with myeloma, idiotype vaccination of sibling donors with the unique tumor-specific immunoglobulin produced by the patient myeloma cells followed by adoptive transfer in the setting of allogeneic stem cell transplantation can result in the induction of antitumor immunity (39). In the setting of autologous HSCT for pediatric neuroblastoma, adoptive transfer of T cells on day 2 was superior to infusions on days 12 or 90 after stem cell infusion, using T cell receptor (TCR) repertoire diversity and the humoral response to a pneumococcal vaccine as endpoints (40). Similarly, in a phase I/II trial involving adult patients with myeloma, transfer of costimulated T cells on Day +2 was followed by vaccination with a multipeptide tumor antigen vaccine derived from the human telomerase reverse transcriptase and the antiapoptotic protein survivin. Patients receiving T cell transfer showed accelerated polyclonal immunoglobulin recovery but no improvement in overall survival (41).

\section{Strategies with CAR T Cells}

To overcome tolerance to tumors that results from deficiencies in the TCR repertoire, T cells are genetically modified with CARs containing sequences that encode antibody-based recognition domains linked to signaling sequences (Figure 1). An advantage of CARs is that because they are specific for cell-surface molecules, they overcome the constraints of MHCrestricted TCR recognition and avoid tumor escape through impairments in antigen presentation or human leukocyte antigen expression. Genetic modification of $\mathrm{T}$ cells is not limited to conferring new antigen reactivity on recipient $\mathrm{T}$ cells but can also be used to insert genes that improve the efficacy of the T cells that are transduced. Such genes include those encoding molecules involved in costimulation (42), the prevention of apoptosis (43), the remodeling of the tumor microenvironment (44), and the induction of homeostatic proliferation (45), as well as CARs encoding chemokine receptors that promote directed $\mathrm{T}$ cell homing (46).

\section{CURRENT STATUS OF CHIMERIC ANTIGEN RECEPTOR T CELL THERAPY}

The design of CARs in clinical trials can be roughly classified into three generations. Firstgeneration CARs encode antibody-based external receptor structures and cytosolic domains that encode signal transduction modules composed of the immunoreceptor tyrosine-based activation motif such as TCR $\zeta$ or FcR $\gamma$ (47). Second-generation CARs also include a 
costimulatory signaling domain such as CD28 or 4-1BB $(48,49)$, and third-generation

CARs include three or more cytosolic domains (50).

\section{First-Generation CARs}

The first CAR trials were conducted in patients with HIV, testing a first-

generationCD4弓CAR that demonstrated modest antiviral efficacy but excellent rates of longterm persistence that may exceed that of natural $\mathrm{T}$ cells (51). Encouragingly, retroviral integration site analysis showed no evidence of persistent clonal expansion or enrichment of integration sites near oncogenes or tumor suppressor genes (34).

A phase I trial testing $\mathrm{T}$ cells expressing a CAR specific for a folate-binding protein that is present on ovarian carcinoma cells indicated that the approach was safe, but poor expression and persistence of the transgene encoding the CAR were observed in vivo (52). Similarly, a pilot test in children with neuroblastoma treated with autologous $\mathrm{T}$ cells retargeted for a tumor-associated adhesion molecule (CD171) has indicated that the approach is safe but was limited by poor persistence of the $\mathrm{T}$ cells (53). $\mathrm{T}$ cells expressing a CAR specific for carbonic anhydrase IX, an antigen present on the surface of clear cell renal cell carcinoma, have also been tried (54). An unexpected serious hepatic toxicity was observed in several patients within a week of T cell infusion, likely due to carbonic anhydrase IX expression in the biliary tract. This study indicates that CAR targets must be carefully chosen to avoid offtumor but on-target adverse effects, or that additional safety features, such as suicide switches or transient expression systems (55), need to be incorporated into the vectors driving the expression of the chimeric receptor.

One lesson from the trials testing first-generation CAR T cells was that the infused product could be immunogenic. Both B cell $(52,54)$ and $\mathrm{T}$ cell responses $(56,57)$ have been identified in CAR trials. In the trial by Lamers and colleagues, the plasma from these patients neutralized target cell recognition by the CAR T cells. In addition, Lamers et al. (57) have shown that eight of nine evaluable patients also developed cellular immunity against their carbonic anhydrase IX-specific CAR, and that patients who developed a B cell response against the CAR also exhibited a cellular response against CAR T cells, but not necessarily the other way around.

The best persistence of CARs reported was in the pediatric neuroblastoma trial (clinicaltrials.gov NCT00085930), where CARs could be detected at very low levels

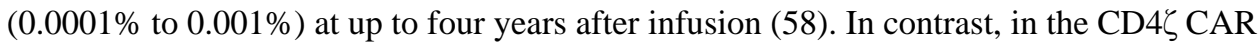
trial (clinicaltrials.gov NCT01013415), the frequency of CAR T cells in blood was several orders of magnitude higher (0.6 to 6\%) five years after infusion (34).

A final discovery from the first-generation CAR trials in cancer patients was that efficacy was disappointing. The best clinical results were reported in patients after infusion of a GD2-specific CAR, with 2 of 11 patients having long-term remissions (58).

\section{Second- and Third-Generation CARs}

Based on principles of $\mathrm{T}$ cell activation (59), it would be predicted that the first-generation CARs would become anergic unless the tumor target provided costimulation, as resting $\mathrm{T}$ 
cells with a CAR containing a TCR $\zeta$ orFcR $\gamma$ signaling moiety cannot be activated in the absence of costimulation $(17,60)$. In 1998, two laboratories showed that the CD28 signaling domain provided costimulation when engineered in cis with the TCR $\zeta$ domain into the CAR design $(48,61)$. It was later shown that members of the tumor necrosis factor receptor family such as CD27, 4-1BB (CD137), and OX40 (CD134) can also provide costimulation (62-64). Many trials are currently ongoing to test second- and third-generation CARs (reviewed in $65,66)$.

\section{CAR Trials Targeting B Cell Malignancies}

Other than normal B cells, CD19 is not present on normal tissues (including pluripotent hematopoietic stem cells) and is not shed as a soluble form into the circulation, making it an excellent target. Promising results in chemotherapy-refractory patients have been obtained targeting the B cell lineage-restricted CD19 molecule that is expressed on B cell leukemias and lymphomas with CD19-specific CAR T cells (18, 67-69). Durable remissions beyond two years have been observed in the initial cohort of patients with refractory and relapsed B cell chronic lymphocytic leukemia (CLL) after the infusion of autologous $\mathrm{T}$ cells transduced to express a CD19-specific CAR that contained a 4-1BB costimulatory domain $(18,19)$. In these studies, the infusion of low doses of $\mathrm{T}$ cells led to massive in vivo expansion, subsequent tumor lysis, and a persistent aplasia of normal CD19+ B cells in most patients (18). Significant antitumor activity, depletion of normal B cells, and side effects related to tumor lysis and cytokine release have also been reported in patients with CLL and lymphoma by groups at the National Institutes of Health, Memorial Sloan-Kettering Cancer Center, and Baylor College of Medicine. In trials by these groups, autologous T cells were modified to express CD19 CARs that contain a CD28 co-stimulatory domain (67-70). In addition to activity in CLL and mantle cell lymphoma (18, 50), CD19:4-1BB CARs have potent activity in pediatric acute lymphoblastic leukemia (ALL) with efficient trafficking to bone marrow and cerebral spinal fluid (71). It is currently unknown whether CARs with a CD28 and/or a 4-1BB signaling domain are preferable. A clinical trial led by Brentjens and collaborators infusing an equivalent number of CD19-specific CARs containing either a CD28 or 4-1BB domain is under way to address this issue (clinicaltrials.gov NCT01044069).

The above trials employed efficient retroviral or lentiviral vector transduction to introduce CARs into T cells. Whether one vector is superior remains unknown. An ongoing trial (clinicaltrials.gov NCT00968760) is testing CD19 CARs that are expressed using the nonviral-vector-mediated sleeping beauty transposon system (72).

Permanent genetic modification, despite considerable safety data, remains a focus of significant regulatory oversight. Several groups have integrated "suicide genes" into their T cell-engineering protocols, in which expression of a proapoptotic gene is under the control of an inducible promoter responsive to a systemically delivered drug (73). Though theoretically attractive, this approach does not guarantee elimination of all modified $\mathrm{T}$ cells, and thus may permit re-expansion of remaining CAR $\mathrm{T}$ cells after clearance of the activating drug. 
An mRNA electroporation-based system to induce transient CAR expression results in efficient CAR delivery and expression that ensure $100 \%$ loss of CAR-driven T cell activity within seven days without the need to administer other systemic agents $(21,74)$. RNA CART cells have demonstrated antigen-driven in vitro effector function $(75,76)$ and in vivo antitumor efficacy in localized models of solid and liquid tumors $(74,77,78)$. It is highly probable that multiple infusions of RNA-modified CAR T cells would be needed for tumor control, and the dose and $\mathrm{T}$ cell composition of these infusions are under investigation.

There are many other questions about the use of CARs for B cell malignancies, including major issues in clinical trial design, such as whether to provide cytokine support to the patient after CAR infusion and whether host conditioning chemotherapy is necessary or desirable.

\section{Toxicity with CAR T Cells}

As with all cancer therapies that have efficacy, there is an emerging set of toxicities associated with $\mathrm{T}$ cell therapies. The toxicities can be classified as those due to extrinsic factors present in the culture process, those due to accompanying cytokines that can be coinfused with the cells, and those due to the cells themselves. Respiratory obstruction has been reported following cytotoxic T lymphocyte infusion for Epstein-Barr virus (EBV)related lymphomas (79). This is probably due to a T cell-induced inflammatory response that results in tumor edema and necrosis. Effector functions of infused $\mathrm{T}$ cells can be expected to include tissue damage similar to that encountered in T cell-mediated autoimmune diseases. In the case of allogeneic lymphocyte infusions, graft-versus-host disease (GVHD) and bone marrow aplasia can occur (80).

On-target toxicities were expected with CD19 CAR T cells and include B cell aplasia, tumor lysis syndrome (TLS), and cytokine release syndrome (CRS). Intravenous immunoglobulin can be used to replace quantitative antibody deficiency. TLS has been managed successfully by standard supportive therapy, including hydration, alkalinization, allopurinol, and rasburicase as required (81). A unique feature of the TLS following CAR T cell therapy is that it may be delayed, occurring one month or more after CAR T cell infusion (19).

In patients with B cell malignancies, a delayed CRS occurs at the time of peak levels of CAR T cells in blood and bone marrow. The optimal management of CRS is still an open question. Corticosteroids and cytokine blockade are currently being evaluated for patients with CLL (clinicaltrials.gov NCT01029366) and ALL (NCT01626495). To mitigate ontarget but off-organ toxicity to normal tissues, novel strategies such as regulating CAR expression or $\mathrm{T}$ cell survival are needed.

A number of off-target toxicities are theoretically possible with CAR T cells. The introduction of CARs by integrating retroviral or lentiviral vectors, transposons, and electroporation all create the risk of malignant transformation, induction of $\mathrm{T}$ cell lymphoproliferative disorders, or production of replication-competent virus. These risks appears to be low based on the long-term follow-up data in patients treated with the CD4ל CAR, where there have been no cases of genotoxicity in > 540 patient-years of observation, and the fact that since the advent of modern packaging cell lines and plasmid designs no 
replication-competent virus has been observed in 297 humans enrolled on 29 different clinical protocols $(34,82)$.

\section{CAR T Cells and Allogeneic Stem Cell Transplant}

Leukemia relapse remains a major cause of failure after allogeneic hematopoietic cell transplant, and the long-sought goal of augmenting the graft-versus-leukemia (GVL) effect without aggravating GVHD remains elusive (83). Unmodified donor lymphocyte infusions are commonly given to treat relapse and are often complicated by GVHD. In addition, although they are dramatically effective for relapsed chronic myeloid leukemia, there is limited activity for patients with relapsed ALL. It is possible that infusion of allogeneic CAR-modified T cells could enhance the efficacy of allogeneic HSCT or improve outcomes of donor lymphocyte infusions. This is supported by recent evidence that infusion of costimulated but non-gene-modified allogeneic T cells was safe in a phase I trial (84). In addition, a pediatric patient treated at the Children's Hospital of Philadelphia relapsed with ALL after a cord blood transplant and had T cells harvested from the patient and returned without induction of GVHD (71). Several trials are now under way to evaluate the safety and antileukemic potential of CAR-modified allogeneic T cell infusions.

\section{ISSUES IN THE FIELD}

One major issue is whether $\mathrm{T}$ cell therapy can enter the routine practice of medicine. Another is whether successful therapies can extend beyond CD19-directed CAR T cells.

\section{Strategies to Use Engineered T Cells as a Bridge to Transplant}

Given the limited therapeutic efficacy of rein-duction regimens for relapsed ALL, the development of engineered $\mathrm{T}$ cells may provide an appropriate bridge to transplant by inducing a remission that can then be preserved by an allogeneic transplant. In patients who have undergone a transplant, it may be possible to utilize the CAR-transduced T cells for treatment of relapse instead of donor lymphocyte infusions. The possibility of utilizing viralspecific $\mathrm{T}$ cells as the transduced cell population can further reduce the likelihood of a concomitant graft-versus-host reaction and may be manipulable by various vaccine strategies.

\section{Does Dose Matter?}

Doses of adoptively transferred cells are usually reported as the total number of viable cells administered, or as the total number of viable cells administered per kilogram body weight or per square meter body surface area. The optimal dose is unknown because T cells with high replicative potential will expand in the host, with the infused total dose having little relation to the steady-state number of cells that engraft and persist. Therefore, dose considerations are more complex than in other areas of transfusion medicine, as red cells or platelets do not expand after transfusion. In our studies of adoptively transferred autologous CAR T cells, we often find that the number of cells in the host peaks two to three weeks after infusion of the cells (18). 
Cytokines given to the host can also have a major impact on the persistence of adoptively transferred $\mathrm{T}$ cells. Others have found that the persistence of adoptively transferred human $\mathrm{CD}^{+}$Tcells is enhanced by coadministration of interleukin (IL)-2 (85). However, we have found that when autologous human $\mathrm{CD} 4^{+} \mathrm{T}$ and $\mathrm{CD} 8^{+} \mathrm{T}$ cells are given in combination, persistence is not increased by concomitant IL-2 therapy (86). Finally, recent studies show that IL-2 can induce the proliferation and maintenance of effector $\mathrm{CD} 8^{+} \mathrm{T}$ cells but might actually delete memory $\mathrm{T}$ cells and increase the number of T regs (87). By contrast, IL-15 and IL-7 seem to select for the persistence of memory CD8 ${ }^{+} \mathrm{T}$ cells and might decrease the number of $\mathrm{T}$ regs in mice (88) and nonhuman primates (89).

Striking schedule-dependent increases in efficacy and the frequency of adverse effects from adoptively transferred cells have been reported when $\mathrm{T}$ cell infusions are given to lymphopenic hosts (90-92). Lymphodepleting chemotherapy is generally administered to the host several days before the adoptively transferred $\mathrm{T}$ cells. The drugs may have multiple effects that seem to promote the antitumor effects of the adoptively transferred T cells (7). Cell dose, T cell replicative capacity, cytokine support, host lymphopenia, and timing of infusion are variables that require more data before optimal regimens can be identified.

\section{FUTURE DIRECTIONS}

The field of adoptive therapy with engineered $\mathrm{T}$ cells is poised for substantial clinical advances that are now possible because of improved cell-culture and gene-transfer methods. In some cases, engineered autologous T cells may obviate the need for allogeneic HSCT, so that it is conceivable that autologous HSCT with T cell infusions could reach or exceed the efficacy of allogeneic HSCT but without the risk of GVHD. A major challenge will be to identify unique tumor antigens that can be targeted with selective T cell therapy. However, the major challenge currently facing the field is to conduct randomized clinical trials demonstrating sufficient clinical benefit to justify the logistics and expense of customized cellular therapies.

\section{Glossary}

CAR chimeric antigen receptor

HSCT hematopoietic stem cell transplantation

\section{LITERATURE CITED}

1. Mitchison NA. Studies on the immunological response to foreign tumor transplants in the mouse. I. The role of lymph node cells in conferring immunity by adoptive transfer. J. Exp. Med. 1955; 102:157-177. [PubMed: 13242741]

2. Barnes DW, Ford CE, Ilbery PL, et al. Tissue transplantation in the radiation chimera. J. Cell. Physiol. Suppl. 1957; 50:123-138. [PubMed: 13513683]

3. Barnes DW, Loutit JF. Treatment of murine leukaemia with x-rays and homologous bone marrow. II. Br. J. Haematol. 1957; 3:241-252. [PubMed: 13460193]

4. Mathe G, Amiel JL, Schwarzenberg L, et al. Adoptive immunotherapy of acute leukemia: experimental and clinical results. Cancer Res. 1965; 25:1525-1531. [PubMed: 5323965]

5. Rosenberg SA, Terry WD. Passive immunotherapy of cancer in animals and man. Adv. Cancer Res. 1977; 25:323-388. [PubMed: 326003] 
6. Weiden PL, Flournoy N, Thomas ED, et al. Antileukemic effect of graft-versus-host disease in human recipients of allogeneic-marrow grafts. N. Engl. J. Med. 1979; 300:1068-1073. [PubMed: 34792]

7. Klebanoff CA, Khong HT, Antony PA, et al. Sinks, suppressors and antigen presenters: how lymphodepletion enhances T cell-mediated tumor immunotherapy. Trends Immunol. 2005; 26:111117. [PubMed: 15668127]

8. Dummer W, Niethammer AG, Baccala R, et al. T cell homeostatic proliferation elicits effective antitumor autoimmunity. J. Clin. Invest. 2002; 110:185-192. [PubMed: 12122110]

9. Hinrichs C, Borman Z, Cassard L, et al. Adoptively transferred effector cells derived from nä1ve rather than central memory CD8 T cells mediate superior antitumor immunity. Proc. Natl. Acad. Sci. USA. 2009; 106:17469-17474. [PubMed: 19805141]

10. Berger C, Jensen MC, Lansdorp PM, et al. Adoptive transfer of effector CD8+ T cells derived from central memory cells establishes persistent T cell memory in primates. J. Clin. Invest. 2008; 118:294-305. [PubMed: 18060041]

11. Paulos CM, Carpenito C, Plesa G, et al. The inducible costimulator ICOS is critical for the development of human TH17 cells. Sci. Transl. Med. 2010; 2:55-78.

12. Gattinoni L, Lugli E, Ji Y, et al. A human memory T cell subset with stem cell-like properties. Nat. Med. 2011; 17:1290-1297. [PubMed: 21926977]

13. Lee JC, Hayman E, Pegram HJ, et al. In vivo inhibition of human CD19-targeted effector T cells by natural T regulatory cells in a xenotransplant murine model of B cell malignancy. Cancer Res. 2011; 71:2871-2881. [PubMed: 21487038]

14. Zhou J, Shen X, Huang J, et al. Telomere length of transferred lymphocytes correlates with in vivo persistence and tumor regression in melanoma patients receiving cell transfer therapy. J. Immunol. 2005; 175:7046-7052. [PubMed: 16272366]

15. Weng NP, Levine BL, June CH, et al. Regulated expression of telomerase activity in human T lymphocyte development and activation. J. Exp. Med. 1996; 183:2471-2480. [PubMed: 8676067]

16. Chen ML, Pittet MJ, Gorelik L, et al. Regulatory T cells suppress tumor-specific CD8 T cell cytotoxicity through TGF- $\beta$ signals in vivo. Proc. Natl. Acad. Sci. USA. 2005; 102:419-424. [PubMed: 15623559]

17. Loskog A, Giandomenico V, Rossig C, et al. Addition of the CD28 signaling domain to chimeric T-cell receptors enhances chimeric T-cell resistance to T regulatory cells. Leukemia. 2006; 20:1819-1828. [PubMed: 16932339]

18. Kalos M, Levine BL, Porter DL, et al. T cells expressing chimeric receptors establish memory and potent antitumor effects in patients with advanced leukemia. Sci. Transl. Med. 2011; 3 95ra73.

19. Porter DL, Levine BL, Kalos M, et al. Chimeric antigen receptor-modified T cells in chronic lymphoid leukemia. N. Engl. J. Med. 2011; 365:725-733. [PubMed: 21830940]

20. Zhao Y, Moon E, Carpenito C, et al. Multiple injections of electroporated autologous T cells expressing a chimeric antigen receptor mediate regression of human disseminated tumor. Cancer Res. 2010; 70:9062-9072. [PubMed: 20884630]

21. Barrett DM, Zhao Y, Liu X, et al. Treatment of advanced leukemia in mice with mRNA engineered T cells. Hum. Gene Ther. 2011; 22:1575-86. [PubMed: 21838572]

22. Seder RA, Darrah PA, Roederer M. T-cell quality in memory and protection: implications for vaccine design. Nat. Rev. Immunol. 2008; 211:58-66.

23. Levine BL, Bernstein W, Craighead N, et al. Effects of CD28 costimulation on long term proliferation of CD4+ T cells in the absence of exogenous feeder cells. J. Immunol. 1997; 159:5921-5930. [PubMed: 9550389]

24. Maus MV, Kovacs B, Kwok WW, et al. Extensive replicative capacity of human central memory T cells. J. Immunol. 2004; 172:6675-6683. [PubMed: 15153483]

25. Zhang H, Snyder K, Suhoski MM, et al. 4-1BB is superior to CD28 costimulation for generating CD8+ cytotoxic lymphocytes for adoptive immunotherapy. J. Immunol. 2007; 179:4910-4918. [PubMed: 17878391]

26. Turtle C, Swanson H, Fujii N, et al. A distinct subset of self-renewing human memory CD8+ T cells survives cytotoxic chemotherapy. Immunity. 2009; 31:834-844. [PubMed: 19879163] 
27. June $\mathrm{CH}$, Blazar BR, Riley JL. Engineering lymphocyte subsets: tools, trials and tribulations. Nat. Rev. Immunol. 2009; 9:704-716. [PubMed: 19859065]

28. Miller AD, Rosman GJ. Improved retroviral vectors for gene transfer and expression. Biotechniques. 1989; 7:980-990. [PubMed: 2631796]

29. Naldini L, Blomer U, Gallay P, et al. In vivo gene delivery and stable transduction of nondividing cells by a lentiviral vector. Science. 1996; 272:263-267. [PubMed: 8602510]

30. Su Z, Dannull J, Yang BK, et al. Telomerase mRNA-transfected dendritic cells stimulate antigenspecific CD8+ and CD4+ T cell responses in patients with metastatic prostate cancer. J. Immunol. 2005; 174:3798-3807. [PubMed: 15749921]

31. Chen YY, Galloway KE, Smolke CD. Synthetic biology: advancing biological frontiers by building synthetic systems. Genome Biol. 2012; 13:240. [PubMed: 22348749]

32. Hacein-Bey-Abina S, Garrigue A, Wang GP, et al. Insertional oncogenesis in 4 patients after retrovirus-mediated gene therapy of SCID-X1. J. Clin. Invest. 2008; 118:3132-3142. [PubMed: 18688285]

33. Muul LM, Tuschong LM, Soenen SL, et al. Persistence and expression of the adenosine deaminase gene for 12 years and immune reaction to gene transfer components: long-term results of the first clinical gene therapy trial. Blood. 2003; 101:2563-2569. [PubMed: 12456496]

34. Scholler J, Brady T, Binder-Scholl G, et al. Decade-long safety and function of retroviral-modified chimeric antigen receptor T cells. Sci. Transl. Med. 2012; 4 132ra53.

35. Dudley ME, Yang JC, Sherry R, et al. Adoptive cell therapy for patients with metastatic melanoma: evaluation of intensive myeloablative chemoradiation preparative regimens. J. Clin. Oncol. 2008; 26:5233-5239. [PubMed: 18809613]

36. Teshima T, Liu C, Lowler KP, et al. Donor leukocyte infusion from immunized donors increases tumor vaccine efficacy after allogeneic bone marrow transplantation. Cancer Res. 2002; 62:796800. [PubMed: 11830535]

37. Mori S, Kocak U, Shaw JL, et al. Augmentation of post transplant immunity: antigen encounter at the time of hematopoietic stem cell transplantation enhances antigen-specific donor T-cell responses in the post transplant repertoire. Bone Marrow Transplant. 2005; 35:793-801. [PubMed: 15750607]

38. Wang LX, Shu SY, Plautz GE. Host lymphodepletion augments T cell adoptive immunotherapy through enhanced intratumoral proliferation of effector cells. Cancer Res. 2005; 65:9547-9554. [PubMed: 16230420]

39. Sumegi J, Nestheide SV, Barnes MG, et al. Gene expression signatures differ between different clinical forms of familial hemophagocytic lymphohistiocytosis. Blood. 2013; 121:e14-e24. [PubMed: 23264592]

40. Grupp SA, Prak EL, Boyer J, et al. Adoptive transfer of autologous T cells improves T cell repertoire diversity and long term $\mathrm{B}$ cell function in pediatric patients with neuroblastoma. Clin. Cancer Res. 2012; 18:6732-6741. [PubMed: 23092876]

41. Rapoport AP, Aqui NA, Stadtmauer EA, et al. Combination immunotherapy using adoptive T-cell transfer and tumor antigen vaccination on the basis of hTERT and survivin after ASCT for myeloma. Blood. 2011; 117:788-797. [PubMed: 21030558]

42. Krause A, Guo HF, Latouche JB, et al. Antigen-dependent CD28 signaling selectively enhances survival and proliferation in genetically modified activated human primary T lymphocytes. J. Exp. Med. 1998; 188:619-626. [PubMed: 9705944]

43. Charo J, Finkelstein SE, Grewal N, et al. Bcl-2 overexpression enhances tumor-specific T-cell survival. Cancer Res. 2005; 65:2001-2008. [PubMed: 15753400]

44. Kerkar SP, Goldszmid RS, Muranski P, et al. IL-12 triggers a programmatic change in dysfunctional myeloid-derived cells within mouse tumors. J. Clin. Invest. 2011; 121:4746-4757. [PubMed: 22056381]

45. Cheng LE, Ohlen C, Nelson BH, et al. Enhanced signaling through the IL-2 receptor in CD8+ T cells regulated by antigen recognition results in preferential proliferation and expansion of responding CD8+ T cells rather than promotion of cell death. Proc. Natl. Acad. Sci. USA. 2002; 99:3001-3006. [PubMed: 11867736] 
46. Moon E, Carpenito C, Sun J, et al. Functional CCR2 receptor enhances tumor localization and eradication by human $\mathrm{T}$ cells expressing a mesothelin-specific chimeric antibody receptor. Clin. Cancer Res. 2011; 17:4719-4730. [PubMed: 21610146]

47. Eshhar Z, Waks T, Bendavid A, et al. Functional expression of chimeric receptor genes in human T cells. J. Immunol. Methods. 2001; 248:67-76. [PubMed: 11223069]

48. Krause A, Guo HF, Latouche JB, et al. Antigen-dependent CD28 signaling selectively enhances survival and proliferation in genetically modified activated human primary T lymphocytes. J. Exp. Med. 1998; 188:619-626. [PubMed: 9705944]

49. Milone MC, Fish JD, Carpenito C, et al. Chimeric receptors containing CD137 signal transduction domains mediate enhanced survival of T cells and increased antileukemic efficacy in vivo. Mol. Ther. 2009; 17:1453-1464. [PubMed: 19384291]

50. Till BG, Jensen MC, Wang J, et al. CD20-specific adoptive immunotherapy for lymphoma using a chimeric antigen receptor with both CD28 and 4-1BB domains: pilot clinical trial results. Blood. 2012; 119:3940-3950. [PubMed: 22308288]

51. Deeks SG, Wagner B, Anton PA, et al. A phase II randomized study of HIV-specific T-cell gene therapy in subjects with undetectable plasma viremia on combination anti-retroviral therapy. Mol. Ther. 2002; 5:788-797. [PubMed: 12027564]

52. Kershaw MH, Westwood JA, Parker LL, et al. A phase I study on adoptive immunotherapy using gene-modified T cells for ovarian cancer. Clin. Cancer Res. 2006; 12:6106-6115. [PubMed: 17062687]

53. Park JR, DiGiusto DL, Slovak M, et al. Adoptive transfer of chimeric antigen receptor re-directed cytolytic T lymphocyte clones in patients with neuroblastoma. Mol. Ther. 2007; 15:825-833. [PubMed: 17299405]

54. Lamers CH, Sleijfer S, Vulto AG, et al. Treatment of metastatic renal cell carcinoma with autologous T-lymphocytes genetically retargeted against carbonic anhydrase IX: first clinical experience. J. Clin. Oncol. 2006; 24:e20-e22. [PubMed: 16648493]

55. Di Stasi A, Tey SK, Dotti G, et al. Inducible apoptosis as a safety switch for adoptive cell therapy. N. Engl. J. Med. 2011; 365:1673-1683. [PubMed: 22047558]

56. Jensen M, Popplewell L, Cooper L, et al. Anti-transgene rejection responses contribute to attenuated persistence of adoptively transferred CD20/CD19-specific chimeric antigen receptor redirected T cells in humans. Biol. Blood Marrow Transplant. 2010; 16:1245-1256. [PubMed: 20304086]

57. Lamers C, Willemsen R, van Elzakker P, et al. Immune responses to transgene and retroviral vector in patients treated with ex vivo engineered T cells. Blood. 2011; 117:72-82. [PubMed: 20889925]

58. Louis CU, Savoldo B, Dotti G, et al. Anti-tumor activity and long-term fate of chimeric antigen receptor positive T-cells in patients with neuroblastoma. Blood. 2011; 118:6050-6056. [PubMed: 21984804]

59. Bretscher P, Cohn M. A theory of self-nonself discrimination. Science. 1970; 169:1042-1049. [PubMed: 4194660]

60. Brocker T. Chimeric Fv-xi or Fv-epsilon receptors are not sufficient to induce activation or cytokine production in peripheral T cells. Blood. 2000; 96:1999-2001. [PubMed: 10961908]

61. Finney HM, Lawson ADG, Bebbington CR, et al. Chimeric receptors providing both primary and costimulatory signaling in T cells from a single gene product. J. Immunol. 1998; 161:2791-2797. [PubMed: 9743337]

62. Imai C, Mihara K, Andreansky M, et al. Chimeric receptors with 4-1BB signaling capacity provoke potent cytotoxicity against acute lymphoblastic leukemia. Leukemia. 2004; 18:676-684. [PubMed: 14961035]

63. Finney HM, Akbar AN, Lawson ADG. Activation of resting human primary T cells with chimeric receptors: costimulation from $\mathrm{CD} 28$, inducible costimulator, $\mathrm{CD} 134$, and CD137 in series with signals from the TCR zeta chain. J. Immunol. 2004; 172:104-113. [PubMed: 14688315]

64. Song D-G, Ye Q, Poussin M, et al. CD27 costimulation augments the survival and antitumor activity of redirected human T cells in vivo. Blood. 2012; 119:696-706. [PubMed: 22117050] 
65. Kohn DB, Dotti G, Brentjens R, et al. CARS on track in the clinic: report of a meeting organized by the Blood and Marrow Transplant Clinical Trials Network (BMT CTN) sub-committee on cell and gene therapy, Washington, DC, May 18, 2010. Mol. Ther. 2011; 19:432-438. [PubMed: 21358705]

66. Jena B, Dotti G, Cooper L. Redirecting T-cell specificity by introducing a tumor-specific chimeric antigen receptor. Blood. 2010; 116:1035-1044. [PubMed: 20439624]

67. Kochenderfer J, Wilson W, Janik J, et al. Eradication of B-lineage cells and regression of lymphoma in a patient treated with autologous Tcells genetically-engineered to recognize CD19. Blood. 2010; 116:4099-4102. [PubMed: 20668228]

68. Kochenderfer JN, Dudley ME, Feldman SA, et al. B-cell depletion and remissions of malignancy along with cytokine-associated toxicity in a clinical trial of anti-CD19 chimeric-antigen-receptortransduced T cells. Blood. 2012; 119:2709-2720. [PubMed: 22160384]

69. Brentjens R, Riviére I, Park J, et al. Safety and persistence of adoptively transferred autologous CD19-targeted T cells in patients with relapsed or chemotherapy refractory B-cell leukemias. Blood. 2011; 118:4817-4828. [PubMed: 21849486]

70. Savoldo B, Ramos CA, Liu E, et al. CD28 costimulation improves expansion and persistence of chimeric antigen receptor-modified T cells in lymphoma patients. J. Clin. Invest. 2011; 121:18221825. [PubMed: 21540550]

71. Grupp SA, Kalos M, Barrett D, et al. Chimeric antigen receptor-modified T cells for acute lymphoid leukemia. N. Engl. J. Med. 2013; 368:1509-1518. [PubMed: 23527958]

72. Kebriaei P, Huls H, Jena B, et al. Infusing CD19-directed T cells to augment disease control in patients undergoing autologous hematopoietic stem-cell transplantation for advanced B-lymphoid malignancies. Hum. Gene Ther. 2012; 23:444-450. [PubMed: 22107246]

73. Di Stasi A, Tey SK, Dotti G, et al. Inducible apoptosis as a safety switch for adoptive cell therapy. N. Engl. J. Med. 2011; 365:1673-1683. [PubMed: 22047558]

74. Zhao Y, Moon E, Carpenito C, et al. Multiple injections of electroporated autologous T cells expressing a chimeric antigen receptor mediate regression of human disseminated tumor. Cancer Res. 2010; 70:9053-9061. [PubMed: 20926399]

75. Birkholz K, Hombach A, Krug C, et al. Transfer of mRNA encoding recombinant immunoreceptors reprograms CD4+ and CD8+ T cells for use in the adoptive immunotherapy of cancer. Gene Ther. 2009; 16:596-604. [PubMed: 19158846]

76. Almasbak H, Rian E, Hoel HJ, et al. Transiently redirected T cells for adoptive transfer. Cytotherapy. 2011; 13:629-640. [PubMed: 21174490]

77. Yoon SH, Lee JM, Cho HI, et al. Adoptive immunotherapy using human peripheral blood lymphocytes transferred with RNA encoding Her-2/neu-specific chimeric immune receptor in ovarian cancer xenograft model. Cancer Gene Ther. 2009; 16:489-497. [PubMed: 19096447]

78. Rabinovich PM, Komarovskaya ME, Wrzesinski SH, et al. Chimeric receptor mRNA transfection as a tool to generate antineoplastic lymphocytes. Hum. Gene Ther. 2009; 20:51-61. [PubMed: 19025415]

79. Heslop HE, Rooney CM. Adoptive cellular immunotherapy for EBV lymphoproliferative disease. Immunol. Rev. 1997; 157:217-222. [PubMed: 9255632]

80. Kernan NA, Collins NH, Juliano L, et al. Clonable T lymphocytes in T cell-depleted bone marrow transplants correlate with development of graft-v-host disease. Blood. 1986; 68:770-773. [PubMed: 3527302]

81. Cairo MS, Coiffier B, Reiter A, et al. Recommendations for the evaluation of risk and prophylaxis of tumour lysis syndrome (TLS) in adults and children with malignant diseases: an expert TLS panel consensus. Br. J. Haematol. 2010; 149:578-586. [PubMed: 20331465]

82. Bear AS, Morgan RA, Cornetta K, et al. Replication-competent retroviruses in gene-modified T cells used in clinical trials: Is it time to revise the testing requirements? Mol. Ther. 2012; 20:246249. [PubMed: 22297819]

83. Alyea EP, DeAngelo DJ, Moldrem J, et al. NCI First International Workshop on the Biology, Prevention and Treatment of Relapse after Allogeneic Hematopoietic Cell Transplantation: report from the committee on prevention of relapse following allogeneic cell transplantation for 
hematologic malignancies. Biol. Blood Marrow Transplant. 2010; 16:1037-1069. [PubMed: 20580849]

84. Porter DL, Levine BL, Bunin N, et al. A phase I trial of donor lymphocyte infusions expanded and activated ex-vivo via CD3/CD28 co-stimulation. Blood. 2006; 107:1325-1331. [PubMed: 16269610]

85. Yee C, Thompson JA, Byrd D, et al. Adoptive T cell therapy using antigen-specific CD8+ T cell clones for the treatment of patients with metastatic melanoma: in vivo persistence, migration, and antitumor effect of transferred T cells. Proc. Natl. Acad. Sci. USA. 2002; 99:16168-16173. [PubMed: 12427970]

86. Mitsuyasu RT, Anton PA, Deeks SG, et al. Prolonged survival and tissue trafficking following adoptive transfer of CD4zeta gene-modified autologous $\mathrm{CD} 4^{+}$and $\mathrm{CD} 8^{+} \mathrm{T}$ cells in human immunodeficiency virus-infected subjects. Blood. 2000; 96:785-793. [PubMed: 10910888]

87. Zhang H, Chua KS, Guimond M, et al. Lymphopenia and interleukin-2 therapy alter homeostasis of CD4+CD25+ regulatory T cells. Nat. Med. 2005; 11:1238-1243. [PubMed: 16227988]

88. Ku CC, Murakami M, Sakamoto A, et al. Control of homeostasis of CD8+ memory T cells by opposing cytokines. Science. 2000; 288:675-678. [PubMed: 10784451]

89. Berger C, Berger M, Hackman RC, et al. Safety and immunologic effects of IL-15 administration in nonhuman primates. Blood. 2009; 114:2417-2426. [PubMed: 19605850]

90. Dudley ME, Wunderlich JR, Robbins PF, et al. Cancer regression and autoimmunity in patients after clonal repopulation with antitumor lymphocytes. Science. 2002; 298:850-854. [PubMed: 12242449]

91. Laport GG, Levine BL, Stadtmauer EA, et al. Adoptive transfer of costimulated T cells induces lymphocytosis in patients with relapsed/refractory non-Hodgkin lymphoma following CD34+selected hematopoietic cell transplantation. Blood. 2003; 102:2004-2013. [PubMed: 12763934]

92. Rapoport AP, Stadtmauer EA, Aqui N, et al. Rapid immune recovery and graft-versus-host diseaselike engraftment syndrome following adoptive transfer of costimulated autologous T cells. Clin. Cancer Res. 2009; 15:4499-4507. [PubMed: 19509133] 

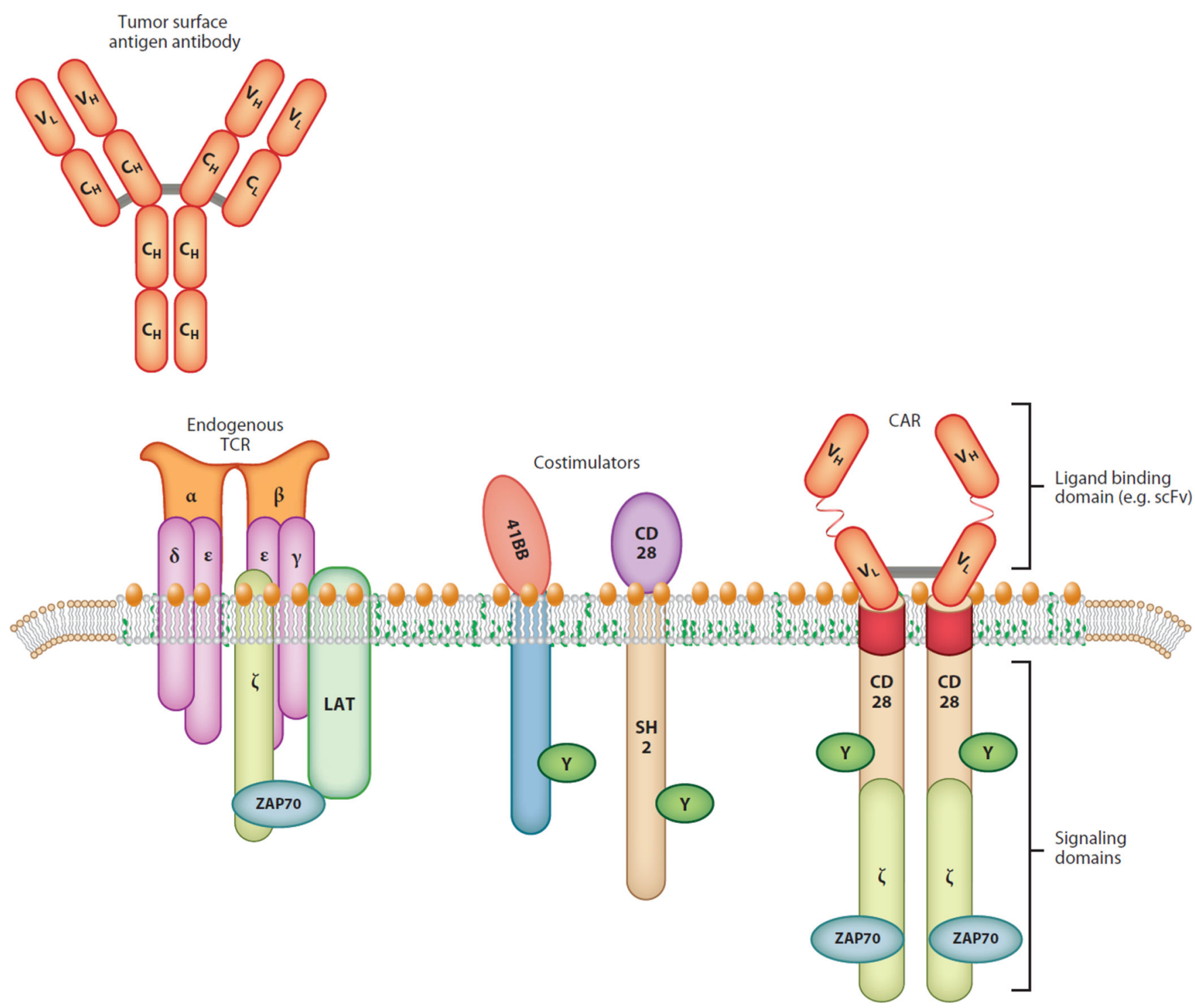

Figure 1.

Antibodies can bind to surface antigens expressed on tumor cells. Chimeric antigen receptors (CARs) have a single-chain antibody fragment ( $\mathrm{scFv}$ ), expressed in tandem with signaling elements derived from the T cell receptor (TCR) and costimulatory domains such as $4-1 B B$ and CD28. 


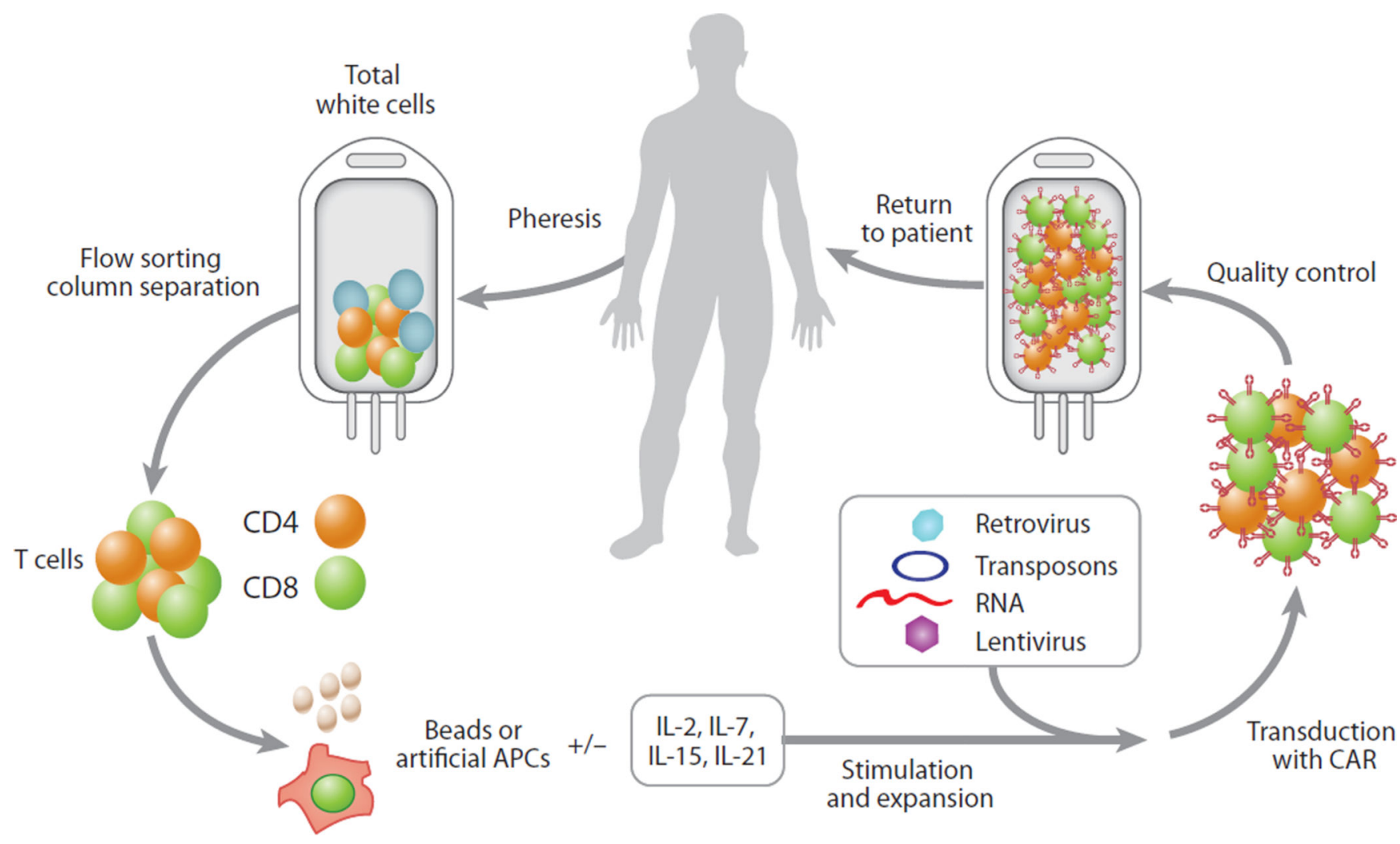

Figure 2.

Chimeric antigen receptor (CAR) therapy is similar to an autologous bone marrow transplantation procedure. $T$ cells are collected from the patient by apheresis, and the $T$ cells are expanded and genetically modified using several approaches before they are returned to the patient. Abbreviation: APCs, antigen-presenting cells. 


\section{Table 1}

\section{Classification of antigenic targets for engineered $\mathrm{T}$ cells}

1. Tissue-specific differentiation antigens that are not tumor specific but may be selected as targets if injury to the normal tissue is tolerable, such as mesothelin in pancreatic cancer and PSA in prostate cancer

2. Cancer-testes (germ cell) antigens, such as NY-ESO-1 and the MAGE family, which are detected in many tumors, such as myeloma and melanoma, but not in normal adult tissues with the exception of the testes

3. Overexpressed self-proteins, particularly those associated with driver mutations, such as c-erbB2 in breast cancer

4. Mutational antigens that are tumor specific, such as $B R A F_{\mathrm{V} 600 \mathrm{E}}$ mutations and $B C R A B L$ translocations

5. Viral antigens which are tumor-specific, such as EBV in HD, HPV in cervical cancer, and polyomavirus in Merkel cancer

6. mHA-specific T cells (allogeneic T cells)

Abbreviations: PSA, prostate-specific antigen; NY-ESO-1, New York esophageal squamous cell carcinoma 1, also known as cancer/testis antigen 1B; MAGE, melanoma associated antigen; EBV, Epstein-Barr virus; HD, Hodgkins disease; HPV, human papillomavirus; mHA, minor histocompatibility antigen. 